\title{
Different formulations of inactivated SARS-CoV-2 vaccine candidates in human compatible adjuvants: Potency studies in mice showed different platforms of immune responses
}

\section{Melika Haghighi}

RVSRi: Razi Vaccine and Serum Research Institute

Akbar khorasani ( $\sim$ akbarkhorasani@gmail.com )

Razi Vaccine and Serum Research Institute https://orcid.org/0000-0002-4259-8843

Pegah Karimi

Motamed Cancer Center

Rouhollah Keshavarz

Razi Vaccine and Serum Research Institute https://orcid.org/0000-0003-4976-1508

Mehdi Mahdavi

Recombinant Vaccine Research Center of TUMS https://orcid.org/0000-0003-4478-5957

\section{Research Article}

Keywords: Inactivated SARS-CoV-2, Adjuvants, Vaccine formulations, Vaccine potency

Posted Date: December 3rd, 2021

DOI: https://doi.org/10.21203/rs.3.rs-1067486/v1

License: (c) (1) This work is licensed under a Creative Commons Attribution 4.0 International License.

Read Full License 


\section{Abstract}

Several inactivated SARS-CoV-2 vaccines were approved for human use but are not highly potent. Here, different formulations of inactivated SARS-CoV-2 virus in Alum, Montanide 51VG and Montanide ISA720VG adjuvants were developed and then immune responses were assessed. SARS-CoV-2 virus was inactivated with formalin and formulated in the adjuvants. BALB/c mice were immunized subcutaneously with $4 \mu \mathrm{g}$ of experimental vaccines on days 0 and 14 and two weeks after the final immunization, IL-4 and IFN- $\gamma$ cytokines, CTL activity and specific IgG titer and IgG1, IgG2a, IgG2a/lgG1 ratio and also anti-RBD IgG response were assessed. Immunization with SARS-CoV-2-Montanide ISA51VG showed a significant increase in IFN- $y$ cytokine versus SARS-CoV-2-Alum, SARS-CoV-2-Montanide ISA720VG and control groups $(P<0.0033)$. Cytokine IL-4 response in SARS-CoV-2-Alum group showed a significant increase versus SARS-CoV-2-Montanide ISA51VG, SARS-CoV-2-Montanide ISA720VG and control groups $(P<0.0206)$. In addition, SARS-CoV-2-Montanide ISA51VG vaccine induced the highest IFN- $\gamma /$ IL-4 cytokine ratio versus other groups $(P<0.0004)$. CTL activity in SARS-CoV-2- Montanide ISA51 VG and SARS-CoV-2Montanide ISA720 VG groups showed a significant increase versus SARS-CoV-2-Alum and control groups $(P<0.0075)$. Specific IgG titer in SARS-CoV-2- Montanide ISA51 VG and SARS-CoV-2-Montanide ISA720VG showed significant increase versus SARS-CoV-2-Alum and control groups $(P<0.0143)$. Results of specific IgG1 and IgG2a level in SARS-COV-2-Alum, SARS-COV-2-Montanide ISA51VG and SARS-COV-2-Montanide ISA720VG vaccine showed a significant increase versus the control group $(P<0.0001)$ but SARS-COV-2Montanide ISA51VG and SARS-COV-2-Montanide ISA 720VG groups showed highest IgG2a/lgG1 ratio and a significant increase versus SARS-COV-2-Alum group $(P<0.0379)$. Results of anti-RBD IgG response showed that inactivated SARS-COV-2+Alum and SARS-COV-2-Montanide ISA 720VG vaccine groups demonstrated a significant increase versus SARS-COV-2-Montanide ISA51VG group.

It seems that the type of vaccine formulation is a critical parameter that effect on immunologic patterns and vaccine potency. Here, results showed that human compatible oil-based adjuvants were more potent than Alum adjuvant in the induction of cellular and humoral immune responses versus SARS-CoV-2 virus.

\section{Introduction}

The COVID-19 pandemic started in December 19 in Wuhan (China). The new SARS-CoV-2 is the seventh member of the Coronaviridae of the order Nidovirales with RNA genome that infects humans and mammals. The World Health Organization named the epidemic a Public Health Emergency of Global Importance in January 2020 and a pandemic in March 2020 (Jeyanathan, Afkhami et al. 2020).

Vaccination is the most effective way to prevent viral infections and it seems that it is important to have a global vaccination to prevent the pandemic (Mahdavi, Ebtekar et al. 2011). SARS CoV-2 transmission occurs with high effectiveness and infectivity, as with other respiratory viruses, predominantly along the respiratory pathway. The most known route is droplet delivery, while aerosols can constitute another significant route (Ciotti, Ciccozzi et al. 2020). As well, financial problem, lost personal freedom and widespread emotional distress caused the increased of mental problems (Pfefferbaum and North 2020). 
Thus, different countries and governments have been paid a high price to prevent the spread and treatment of this disease and also development an efficient vaccine (Wang, Shi et al. 2006). Analysis of the genomes and comparing with the previously identified genomes of coronaviruses show that SARSCoV-2 has distinct characteristics that separate it from the other coronaviruses (Nao, Yamagishi et al. 2017, Andersen, Rambaut et al. 2020). It is believed that SARS-CoV-2 is able to transmit to another species (Shi, Wang et al. 2020). It is clear that both humoral and cellular immune responses are needed to combat and clear the viral infections, so these properties for a successful vaccine should be considered in the vaccine design and also vaccine formulation (Jamali, Mahdavi et al. 2007, Zhu, Li et al. 2020). Different platform of SARS-CoV-2 vaccines are developed such as mRNA vaccine, DNA vaccine, viral vectors, recombinant vaccine and inactivated vaccines which some of these platforms are commercialized and are using in different countries (Frederiksen, Zhang et al. 2020, Kaur and Gupta 2020). Vaccine formulation with adjuvants and other excipients is so critical and effect on the vaccine potency. And these factors influence on vaccine stability and also the type of triggered immune responses which in turn effect on the vaccine efficacy (Fakharzadeh, Kalanaky et al. 2013, Rostami, Ebtekar et al. 2017, Mojarab, Shahbazzadeh et al. 2020). One of the commercialized vaccines for COVID19 is inactivated viral particles which now is using in different countries. Naturally, immunogenicity and potency of inactivated virus is low and formulation in an adjuvant makes it more immunogen (Hotez, Corry et al. 2020, Logunov, Dolzhikova et al. 2020, Wang, Peng et al. 2020).

In this study, we developed different formulations of inactivated SARS-CoV-2 viral particles with different classes of adjuvants and then cellular and humoral immune responses against each formulation of vaccine was assessed in the experimental mice. We have shown that different formulations of vaccine triggered different levels and platforms of immune responses.

\section{Materials And Methods}

Virus isolation, propagation

SARS-CoV-2 virus was isolated from throat/nasal swab sample of a patient (positive in real time PCR) from Karaj, Iran (SARS-CoV-2/human/IRN/Alborz-IR/2020 surface glycoprotein (S) gene, complete cds 3,822 bp linear RNA MW709393.1 GI: 1998262910). The virus replication was performed on Vero cell line which were cultured in Dulbecco's Modified Eagle's Medium (DMEM) supplemented with $5 \%$ heatinactivated fetal bovine serum (FBS) and then confirmed by real-time PCR and gene sequencing (MW709393). For efficient growth in Vero cells, the virus strain was purified by plaque assay. The first purified clone passaged three times on Vero cells to obtain an efficient virus stock. This stock virus shows more efficiency with more than $90 \%$ CPE in 48 hours post infection and a titer 6.5 to $7 \mathrm{TCID} 50 / \mathrm{ml}$. The SARS-CoV-2 propagation carried out in biosafety level-III (BSL-III) facilities.

Virus inactivation and quantification

A SARS-CoV-2 strain was cultivated in Vero cell line for propagation, and the supernatant of the infected cells was inactivated with formalin $0.04 \% \mathrm{vol} / \mathrm{vol}$ at RT for 30 hours (finally 4:10000). Following 
clarification of cell debris concentration were performed by ultrafiltration and 8\% PEG-6000. Purification performed using column chromatography. The purified and inactivated viruses dialyzed versus PBS and passed through 0.22 filter and finally quantified using Bradford method. The quantified virus aliquots stored at $-70^{\circ} \mathrm{C}$ until use.

Vaccines formulation

Inactivated SARS-COV-2 virus was formulated in Montanide ISA 720VG, Montanide ISA51VG (SEPPIC, France), and /or Alum hydroxide (Pasteur Institute of Iran) adjuvants. In order to formulate in oil-based adjuvants, inactivated SARS-COV-2 virus in PBS buffer was admixed with Montanide ISA 720VG (at the ratio of 30/70) and Montanide ISA 51VG (at the ratio of 50/50) by vigorously shaking to develop a milky white suspension and homogenized using homogenizer to develop a homogen suspension. In order to formulate Alum-based vaccine, $4 \mu \mathrm{g}$ of inactivated SARS-COV-2 virus in PBS buffer was mixed with $200 \mu \mathrm{g}$ of Alum hydroxide adjuvant (for each dose of vaccine formulation) and shaked at 100 RPM for 60 minutes at room temperature and allowed that the viral particles adsorb on the surface of Alum gel. All vaccine formulations were performed in the clean room of Department of FmD Vaccine formulation of Razi Vaccine and Serum Institute of Iran (Karaj, Iran). After final vaccine formulation, each $200 \mu$ l of all vaccines contained $4 \mu \mathrm{g}$ of inactivated SARS-COV-2 virus that used for immunization.

Mice and immunization

Six-to eight-week-old male BALB/c mice $(\mathrm{N}=40)$ were purchased from Royan Institute of Iran (Tehran, Iran). The mice were housed for one week before the experiments, given free access to the food and water and maintained in a $12 \mathrm{hrs}$ light $\backslash$ and $12 \mathrm{hrs}$ dark cycles. The experimental mice were handled with an expert technician and in accordance with the Animal Care and Use Protocol of Razi Vaccine and Serum Research Institute of Iran. Experimental mice were randomly divided into four groups and each one consisting of 10 mice as below:

\section{Group 1}

Mice were immunized subcutaneously with $4 \mu \mathrm{g}$ of inactivated SARS-COV-2-Alum vaccine.

\section{Group 2}

Mice were immunized subcutaneously with $4 \mu \mathrm{g}$ of inactivated SARS-COV-2-Montanide ISA-51VG vaccine.

\section{Group 3}

Mice were immunized subcutaneously with $4 \mu \mathrm{g}$ of inactivated SARS-COV-2-Montanidee ISA-720VG vaccine.

\section{Group 4}

Mice were immunized with PBS as control group. 
Experimental groups of mice were immunized subcutaneously two times with14-day-intervals and two weeks after the final immunization immunologic parameters were assessed.

In vitro antigen recall of spleen cells

Two weeks after the second immunization, the spleen of the immunized mice was removed under sterile conditions and mechanically dissected and suspended in the sterile cold PBS containing penicillin and streptomycin. The cell suspension centrifuged at $300 \mathrm{~g} / 5 \mathrm{~min}$ and RBCs were lysed using lysis buffer and single-cell suspension was washed three times and adjusted to $3 \times 10^{6} \mathrm{cells} / \mathrm{ml}$ in RPMI-1640 (Gibco, Germany) supplemented with $10 \%$ FBS, $4 \mathrm{mM} \mathrm{L}$-glutamine, $1 \mathrm{mM}$ sodium pyruvate, $100 \mu \mathrm{g} / \mathrm{ml}$ streptomycin and $100 \mathrm{IU} / \mathrm{ml}$ penicillin. One milliliter of cell suspension containing a total number of $3 \times$ $10^{6}$ spleen cells were seeded in each well of 24-well plates. The spleen cells were then stimulated in vitro with adding $1 \mu \mathrm{g} / \mathrm{ml}$ of inactivated SARS-COV-2 virus and the plates incubated at $37^{\circ} \mathrm{C}$ in $5 \% \mathrm{CO} 2$. After $48 \mathrm{hrs}$ post antigen recall, the culture supernatant were centrifuged at $5000 \mathrm{RPM} / 10 \mathrm{~min}$ and the supernatants were harvested and stored at $-70^{\circ} \mathrm{C}$ for cytokines assay.

IFN- $y$ and IL-4 cytokines ELISA

The quantity of IFN- $\gamma$ and IL-4 cytokines was estimated by quantitative mouse IFN- $\gamma$ and IL-4 cytokine ELISA Kits (Mabtech, Stockholm, Sweden) according to the manufacturer's instruction. The ELISA of IFN$\mathrm{Y}$ and IL-4 cytokines were performed in the present of cytokines standards and using the standard curve of each cytokine. The $\mathrm{pg} / \mathrm{ml}$ of each sample was reported and also for calculating the IFN- $/ \mathrm{IL}-4$ ratio, the quantity of IFN- $\mathrm{y}$ of each mouse was divided into that one of IL-4 cytokine.

\section{CTL assay}

The CTL activity of experimental groups was assessed by Granzyme B (Gr-B) release. Briefly, $1.5 \times 10^{6}$ spleen cells of experimental mice were cultured in 96-well plate and stimulated with $1 \mu \mathrm{g} / \mathrm{ml}$ of inactivated SARS-COV-2 virus. As negative control for each mouse, some wells were cultured without antigen stimulation. The plates were incubated at $37^{\circ} \mathrm{C}$ in $5 \% \mathrm{CO}_{2}$ and after $48 \mathrm{hrs}$ of antigen stimulation; culture supernatants were harvested and were used for Gr-B assay by ELISA according to the manufacturer's instruction (eBioscience, USA). The quantity of Gr-B of stimulated wells was subtracted with unstimulated one of each mouse and used as net Gr-B release as a criterion of CTL activity.

ELISA of specific IgG antibodies titer and their isotypes

Specific antibodies were determined by an optimized indirect ELISA method. Briefly, $100 \mu \mathrm{l} \mathrm{of} 5 \mu \mathrm{g} / \mathrm{ml}$ of inactivated SARS-COV-2 in PBS were added into 96-well ELISA Maxisorp plates (Greiner, Germany) and incubated overnight at $4^{\circ} \mathrm{C}$. The wells washed with PBS containing $0.1 \%$ Tween 20 (washing buffer) and blocked $1 \mathrm{hr}$ at $37^{\circ} \mathrm{C}$ with $2 \%$ skimmed milk in PBS $+0.1 \%$ Tween 20 (blocking buffer). The plates were washed with washing buffer and $100 \mu \mathrm{l}$ of $1 / 25$ diluted sera up to 16 serial dilutions were added into each wells and incubated at $37^{\circ} \mathrm{C}$ for $90 \mathrm{~min}$. The wells washed five times with washing buffer and 
incubated for 2 hrs with $100 \mu$ of 1/8000 dilution of anti-mouse conjugated to HRP (Razirad, Iran). The wells washed five times and incubated 30 min with $100 \mu$ of TMB substrate in the dark and the reaction was stopped with $100 \mu \mathrm{l}$ of $2 \mathrm{~N} \mathrm{H} 2 \mathrm{SO} 4$ and colour density was measured at $450 \mathrm{~nm}$ with ELISA plate reader. The cut off of ELISA for each titer was calculated on 10 sera samples of sham group by formula: Mean+3SD of these samples and based on the cut off the titer of each mouse of the experiments was earned. The final results of antibody titer for each mouse presented as Log10 of antibody titer. In addition, detection of specific IgG1 and IgG2a subclasses were carried out using goat anti-mouse IgG1 and IgG2a secondary antibodies (Sigma, USA) according to the manufacture's instruction.

Assessment of specific IgG anti-RBD protein

The specific $\lg G$ antibody response against RBD protein was determined by a laboratory-optimized indirect ELISA. At the first for antigen coating, $100 \mu \mathrm{l}$ of $2 \mu \mathrm{g} / \mathrm{ml}$ of RBD protein (The Native Antigen Company, UK) in carbonate-bicarbonate buffer with $\mathrm{pH} 9.6$ was added into 96-well ELISA Maxisorp plates (Greiner, Germany) and incubated overnight at $4^{\circ} \mathrm{C}$. The wells were washed with PBS containing $0.1 \%$ tween 20 (washing buffer) and then blocked $1 \mathrm{hr}$ at $37^{\circ} \mathrm{C}$ with $1.5 \% \mathrm{BSA}$ in PBS $+0.05 \%$ tween 20 (blocking buffer). The plates were washed 5 times with washing buffer and $100 \mu$ of $1 / 50$ diluted sera of experimental vaccinated and sham group of mice were added into each well and incubated at $37^{\circ} \mathrm{C}$ for 90 min. The wells were washed 5 times with washing buffer and incubated for 90 min with $100 \mu \mathrm{l}$ of 1/8000 dilution of anti-mouse HRP-conjugate (Razirad, Iran). The wells washed 5 times and incubated 10min with $100 \mu$ l of TMB substrate in the dark and the reaction was stopped by adding $100 \mu \mathrm{l}$ of $2 \mathrm{~N} \mathrm{HCL}$ and colour density was measured at $450 \mathrm{~nm}$ with ELISA plate reader. The cutoff of RBD-ELISA was calculated on the sera samples of sham group by formula: Mean+3SD and then IgG response to RBD for individual mouse was reported by formula; OD of RBD ELISA of individual mouse/cutoff.

\section{Statistical analysis}

The data were presented as mean \pm standard deviation (SD) of each experiment. The statistical significance of differences was analysed using two-way ANOVA followed by Tukey test (Graph Pad Prism 6.01 software, Graph Pad Software, La Jolla, CA). Statistical analysis of antibody titers and IgG isotypes were carried out by the Mann-Whitney $U$ test. In all of the cases, $P$ values less than 0.05 was considered significant difference.

\section{Results}

IFN-y cytokine

The results of IFN-y cytokine in the experimental groups show that only the injection of SARS-COV-2 vaccine formulated in Montanide ISA51VG adjuvant resulted to a significant difference as compared with the control group ( $P=0.0003$ ). In addition, immunization with vaccine-Montanide ISA51VG showed a significant increase in IFN- $y$ response as compared with the vaccines that formulated in Alum and Montanide ISA 720VG adjuvants ( $P=0.0004$ and $P=0.0033$, respectively) (Fig. 1). 
IL-4 cytokine

Immunization with SARS-COV-2-Alum vaccine and SARS-COV-2-Montanide ISA 51VG vaccine showed a significant increase in IL-4 cytokine secretion versus control group ( $P=0.0001$ and $P=0.0288$, respectively). In different vaccine formulations, immunization with SARS-COV-2-Alum vaccine showed a significant increase of IL-4 cytokine response in comparison with SARS-COV-2-Montanide ISA 51VG and SARS-COV2-Montanide ISA 720VG vaccines ( $P=0.0206$ and $P=0.0005$, respectively) (Fig. 2).

IFN-y /IL-4 cytokine ratio

The results of IFN- $-/ \mathrm{IL}-4$ cytokine ratio in the experimental groups revealed that immunization with SARSCOV-2-Montanide ISA51VG vaccine induced the highest IFN- $/$ /L-4 cytokine ratio and in comparison with SARS-COV-2-Alum vaccine, SARS-COV-2-Montanide ISA 720VG and control groups showed significant differences ( $P=0.0001, P=0.0004$ and $P=0.0001$, respectively) (Fig. 3).

CTL response

The results of CTL activity based on Gr-B secretion in the mice which immunized with SARS-COV-2Montanide ISA51VG, SARS-COV-2-Alum and SARS-COV-2-Montanide ISA 720VG vaccines showed a significant increase versus control group $(P=0.0001, P=0.0017$ and $P=0.0001$, respectively). In addition, immunization with SARS-COV-2-Montanide ISA51VG and SARS-COV-2-Montanide ISA 720VG vaccines showed a significant increase in comparison with SARS-COV-2-Alum group $(P=0.0001$ and $P=0.0075$, respectively). But no significant difference in CTL activity was observed between SARS-COV-2 Montanide ISA51VG and SARS-COV-2 Montanide ISA720VG groups ( $P=0.2628$ ) (Fig. 4).

Specific IgG titer

The results of specific IgG titer in the experimental groups demonstrated that immunization with SARSCOV-2-Montanide ISA51VG, SARS-COV-2-Alum and SARS-COV-2-Montanide ISA 720VG vaccines showed a significant increase versus control group $(\mathrm{P}<0.0001)$. Furthermore, immunization with SARS-COV-2Montanide ISA51VG and SARS-COV-2-Montanide ISA 720VG vaccines induced a significant increase of IgG titer in comparison with SARS-COV-2-Alum group ( $\mathrm{P}=0.0143$ and $\mathrm{P}=0.0048$, respectively). There was no significant difference in specific IgG titer between SARS-COV-2-Montanide ISA51VG and SARS-COV-2Montanide ISA720VG groups ( $P=0.6867$ ) (Fig. 5).

Specific IgG1 antibody

The results of specific IgG1 isotype demonstrated that immunization with SARS-COV-2-Montanide ISA51VG, SARS-COV-2-Alum and SARS-COV-2-Montanide ISA 720VG vaccines showed a significant increase versus control group $(P<0.0001)$. The group immunized with SARS-COV-2-Alum induced a significant increase of IgG1 isotype in comparison with SARS-COV-2-Montanide ISA51VG and SARS-COV2-Montanide ISA 720VG vaccines ( $P=0.0043$ and $P=0.0041$, respectively). There was no significant 
difference in specific IgG1 response between SARS-COV-2 Montanide ISA51VG and SARS-COV-2 Montanide ISA720VG groups ( $P=0.4488$ ) (Fig. 6).

Specific IgG2a antibody

The results of specific IgG2a isotype antibody in the experimental groups demonstrated that immunization with SARS-COV-2-Montanide ISA51VG, SARS-COV-2-Alum and SARS-COV-2-Montanide ISA $720 V G$ vaccines showed a small increase versus control group but no significant differences was observed among experimental groups ( $P>0.1550)$ (Fig. 7).

$\lg \mathrm{G} 2 \mathrm{a} / \lg \mathrm{g} 1$ ratio

The results of $\lg \mathrm{G} 2 \mathrm{a} / \lg \mathrm{G} 1$ ratio in the experimental groups demonstrated that immunization with SARSCOV-2-Montanide ISA51VG and SARS-COV-2-Montanide ISA 720VG vaccines resulted to a significant increase versus SARS-COV-2-Alum group $(P=0.0379$ and $P=0.0175$, respectively). While there was no significant difference in IgG2a/lgG1 ratio between SARS-COV-2-Montanide ISA51VG and SARS-COV-2Montanide ISA720VG groups ( $P=0.4458)$ (Fig. 8).

Specific IgG antibodies against RBD protein

Results from anti-RBD IgG response demonstrated that immunization with SARS-COV-2-Montanide ISA51VG, SARS-COV-2-Alum and SARS-COV-2-Montanide ISA 720VG vaccines resulted in a significant increase versus control group $(P<0.0185)$. In addition, immunization with inactivated SARS-COV-2+Alum and SARS-COV-2-Montanide ISA 720VG vaccines showed a significant increase versus SARS-COV-2Montanide ISA51VG group $(P<0.0001)$.

While SARS-COV-2-Alum and SARS-COV-2-Montanide ISA 720VG groups showed a comparable IgG response versus RBD protein and did not show a significant difference versus each other $(P=0.9999)$ (Fig. 9).

\section{Discussion}

With emerging the pandemic of COVID-19 and high mortality rate and fast dissemination, much efforts was put into the development an efficient vaccine (Bos, Rutten et al. 2020). Finally several vaccines for COVID-19 have been developed by a variety of organizations and academic centers, ranging from the inactivated virus and protein-based vaccines to DNA and mRNA-based vaccines with high efficacy in human clinical trials. And some of these vaccines have been approved for human use. One important issue regarding the vaccine potency is the type of adjuvant in the vaccine formulation and its relation to the immunologic patterns and vaccine potency (Peng, Cao et al. 2020, Wang, Peng et al. 2020, Crommelin, Volkin et al. 2021).

Herein, we have developed three different formulations of inactivated SARS-COV-2 vaccines in human compatible adjuvants and focused on the nature of immune responses which triggered by each 
formulation of vaccine to show the critical role of adjuvant and also vaccine formulation in the SARSCOV-2 vaccine model. Here, IFN- $y$ cytokine result shows that inactivated SARS-COV-2-Montanide ISA$51 \mathrm{VG}$ triggered the highest cytokine IFN- $\gamma$ response as compared with the alum- and Montanide ISA720VG-based vaccines. Several studies have shown the potency of Montanide ISA-51VG adjuvant in the polarization toward a strong IFN- $\gamma$ and Th1 response (Atsmon, Kate-llovitz et al. 2012, Soema, van Riet et al. 2015, Savoji, Sereshgi et al. 2021) as we achieved in SARS-COV-2 vaccine model. The role of IFN- $y$ cytokine in the controlling viral infections is well known (Noh 2020). Infected patients with SARS-CoV-2 had a complex trend of IFN- $\alpha$, medium levels of IFN- $\gamma$, and undetectable IFN- $\beta$ and $\lambda$ cytokines (TrouilletAssant, Viel et al. 2020). Several studies have shown that vaccines that induced higher level of IFN- $\gamma$ cytokine, was more protective (Bos, Rutten et al. 2020, Ramasamy, Minassian et al. 2021, Rasmussen, Kelley et al. 2021). Cytokine IL-4 response in the different vaccine formulations showed a strong and dramatic response in Alum-based vaccine and even higher than the oil-based vaccines. It is so-long that the potency of Alum-based vaccines in the induction of IL-4 cytokine response is well known and confirming Th2 response pattern (Bungener, Geeraedts et al. 2008, Serre, Mohr et al. 2010). While formulation of inactivated SARS-COV-2 virus in oil-based adjuvants suppressed IL-4 cytokine response and confirming Th1 pattern in Montanide adjuvanted groups. In addition, IFN- $\mathrm{Y} / \mathrm{IL}-4$ cytokine ratio representing the Th1 cytokine network (Maspi, Ghaffarifar et al. 2017, de la Cruz, Villanueva-Lizama et al. 2019) that considers cytokine Th1 pattern has also increased significantly in Montanide ISA51VG adjuvanted group versus Alum-and Montanide ISA720VG-formulated vaccines. And is another confirm for Th1 polarization in Montanide ISA51VG adjuvanted vaccine group.

In this study, we also used the secretion of Granzyme B as a marker of CTL activity. The results showed that inactivated SARS-COV-2 vaccine based on Montanide ISA-51 VG formulation showed the highest Gr$B$ release meaning the highest $C T L$ activity among the experimental groups. Gr-B triggers a cascade of events within the target cells that infected with virus that lead to induction the apoptosis and cell death (Lord, Rajotte et al. 2003) as well as clearance of viral infection from the lungs (Doherty, Topham et al. 1997). It is well-known that early decrease in TCD8+ population is an important factor in the pathogenesis of COVID-19 infection and improvement of TCD8+ lymphocyte response in the vaccination would be an important mechanism for resistance against COVID-19 infection (Elsaesser, Sauer et al. 2009, Ganji, Farahani et al. 2020, Zheng, Zhang et al. 2020). Here, oil-based adjuvants were more successful than Alum-based vaccine in the induction of CTL response against SARS-COV-2 antigens.

In the next step of study we have focused on the humoral immune responses triggered by each formulation of vaccine. Results from IgG responses based on the end point in ELISA showed that immunization with SARS-COV-2-Montanide ISA-51VG and SARS-COV-2-Montanide ISA-720VG vaccines induced a significant increase in the SARS-COV-2 specific IgG titer in comparison with SARS-COV-2-Alum group. This property of oil-based vaccines is so critical because the basis of protection in COVID-19 infection relies mainly on the specific antibodies, however T cells response is important, too (Juno, Tan et al. 2020, Carrillo, Izquierdo-Useros et al. 2021). 
Various studies have shown that oil-based adjuvanted vaccines are more potent in the induction of antibody response and even T cell responses than Alum-based vaccines (Khorasani, Madadgar et al. 2016, Savoji, Haghighat et al. 2019, Savoji, Sereshgi et al. 2021). Stronger humoral immune responses in the oil-based adjuvanted SARS-COV-2 vaccines versus Alum-based SARS-COV-2 vaccine may be due to the nature of the oil-based adjuvants, because Montanide family adjuvants are able to protect the antigen from denaturation by protease enzymes and free radicals at the injection site. These agents through denaturation the structure of protein decrease the vaccine potency. In addition, several studies have shown the potency of Montanide adjuvant family in the induction of follicular helper $T$ cell that has critical role in the differentiation of plasma cells and humoral immune responses (Aucouturier, Dupuis et al. 2002, Riteau, Radtke et al. 2016, Savoji, Sereshgi et al. 2021).

In addition, IgG isotypes analysis showed that formulation of inactivated SARS-COV-2 virus in Alum adjuvant triggered highest IgG1 response while immunization with SARS-COV-2-Montanide ISA-51VG and SARS-COV-2-Montanide ISA-720VG vaccines showed a tiny increase in IgG2a response and a significant increase in IgG2a/lgG1 ratio versus Alum-based vaccine. Considering that IgG1 as a symbol of Th2 response and IgG2a and IgG2a/lgG1 ratio as a symbol of Th1 response (Mahdavi, Mavandadnejad et al. 2017, Mahdavi, Tajik et al. 2017), this finding shows the potency of oil-based vaccines in the polarization toward Th1 response and also a change in the type of IgG isotypes responses. Furthermore, due to the critical role of RBD protein in the attachment to ACE2 receptor of host cells, and anti-RBD IgG antibody which is considered as a potentially neutralizing factor against SARS-CoV-2 virus, in the next IgG response against RBD protein was assessed which potentially can show neutralization activity (Khoury, Cromer et al. 2021, Starr, Czudnochowski et al. 2021). Results show that inactivated SARS-COV-2+Alum and SARS-COV-2-Montanide ISA 720VG vaccine groups showed a comparable IgG response versus each other against RBD protein an and an increase versus SARS-COV-2-Montanide ISA51VG group. This finding shows that Montanide-based vaccine is able to trigger anti-RBD response like as Alum-based vaccine but oil-based vaccines were superior to Alum-based vaccine in the induction of Th1 cytokine and CTL activity which is critical in the controlling SARS-COV-2 infection.

\section{Conclusion}

In conclusion the results of the present study provide evidences that the type of adjuvant in the vaccine formulation can modifies the type of immune responses and also potency of humoral immune responses. This finding encourages the SARS-COV-2 vaccinologists to focus on the different formulations of vaccine to achieve a more potent and safe vaccine especially for inactivated SARS-COV-2 based vaccines which has fewer efficacies than mRNA-based vaccines.

\section{Declarations}

Acknowledgements This study was partially supported by a grant from Razi Vaccine and Serum Research Institute of Iran (Grant no. 2297/250). The authors are grateful to Borna Zist Pazhohan Knowledge Company and their staffs for funding and technical supports of this project. We also thank 
the staffs of Vaccine Formulation Laboratory from Department of FMD vaccine production of Razi Vaccine and Serum Research Institute of Iran for technical supports.

\section{Compliance with ethical standards}

Conflict of interest The authors declare that they have no conflict of interest.

\section{References}

1. Andersen KG, Rambaut A, Lipkin WI, Holmes EC, Garry RF (2020) "The proximal origin of SARS-CoV2". Nat Med 26(4):450-452

2. Atsmon J, Kate-llovitz E, Shaikevich D, Singer Y, Volokhov I, Haim KY, Ben-Yedidia T (2012) Safety and immunogenicity of multimeric-001-a novel universal influenza vaccine. J Clin Immunol 32(3):595-603

3. Aucouturier J, Dupuis L, Deville S, Ascarateil S, Ganne V (2002) Montanide ISA 720 and 51: a new generation of water in oil emulsions as adjuvants for human vaccines. Expert Rev Vaccines 1(1):111-118

4. Bos R, Rutten L, van der Lubbe JEM, Bakkers MJG, Hardenberg G, Wegmann F, Zuijdgeest D, de Wilde AH, Koornneef A, Verwilligen A, van Manen D, Kwaks T, Vogels R, Dalebout TJ, Myeni SK, Kikkert M, Snijder EJ, Li Z, Barouch DH, Vellinga J, Langedijk JPM, Zahn RC, Custers J, Schuitemaker H (2020) Ad26 vector-based COVID-19 vaccine encoding a prefusion-stabilized SARS-CoV-2 Spike immunogen induces potent humoral and cellular immune responses. NPJ Vaccines 5:91

5. Bungener L, Geeraedts F, Ter Veer W, Medema J, Wilschut J, Huckriede A (2008) Alum boosts TH2type antibody responses to whole-inactivated virus influenza vaccine in mice but does not confer superior protection. Vaccine 26(19):2350-2359

6. Carrillo J, Izquierdo-Useros N, Ávila-Nieto C, Pradenas E, Clotet B, Blanco J (2021) Humoral immune responses and neutralizing antibodies against SARS-CoV-2; implications in pathogenesis and protective immunity. Biochem Biophys Res Commun 538:187-191

7. Ciotti M, Ciccozzi M, Terrinoni A, Jiang W-C, Wang C-B (2020) C. R. i. C. L. S. Bernardini. "The COVID19 pandemic " 57(6):365-388

8. Crommelin DJ, Volkin DB, Hoogendoorn KH, Lubiniecki AS, Jiskoot W (2021) The science is there: key considerations for stabilizing viral vector-based Covid-19 vaccines. J Pharm Sci 110(2):627-634

9. de la Cruz JJ, Villanueva-Lizama L, Dzul-Huchim V, Ramírez-Sierra M-J, Martinez-Vega P, RosadoVallado M, Ortega-Lopez J, Flores-Pucheta Cl, Gillespie P, Zhan B (2019) Production of recombinant TSA-1 and evaluation of its potential for the immuno-therapeutic control of Trypanosoma cruzi infection in mice. Human vaccines \& immunotherapeutics 15(1):210-219

10. Doherty PC, Topham DJ, Tripp RA, Cardin RD, Brooks JW, Stevenson PG (1997) "Effector CD4+ and CD8+ T-cell mechanisms in the control of respiratory virus infections. " Immunol Rev 159:105-117 
11. Elsaesser H, Sauer K, Brooks DG (2009) "IL-21 is required to control chronic viral infection. " Science 324(5934):1569-1572

12. Fakharzadeh S, Kalanaky S, Hafizi M, Goya MM, Masoumi Z, Namaki S, Shakeri N, Abbasi M, Mahdavi M, Nazaran MH (2013) The new nano-complex, Hep-c, improves the immunogenicity of the hepatitis B vaccine. Vaccine 31(22):2591-2597

13. Frederiksen LSF, Zhang Y, Foged C, Thakur A (2020) "The long road toward COVID-19 herd immunity: vaccine platform technologies and mass immunization strategies."Frontiers in immunology 11

14. Ganji A, Farahani I, Khansarinejad B, Ghazavi A, Mosayebi G (2020) Increased expression of CD8 marker on T-cells in COVID-19 patients. Blood Cells, Molecules, and Diseases 83:102437

15. Hotez PJ, Corry DB, Strych U, Bottazzi ME (2020) "COVID-19 vaccines: neutralizing antibodies and the alum advantage". Nat Rev Immunol 20(7):399-400

16. Jamali A, Mahdavi M, Shahabi S, Hassan ZM, Sabahi F, Javan M, Farsani MJ, Parsania M, Bamdad $T$ (2007) Naloxone, an opioid receptor antagonist, enhances induction of protective immunity against HSV-1 infection in BALB/c mice. Microb Pathog 43(5-6):217-223

17. Jeyanathan M, Afkhami S, Smaill F, Miller MS, Lichty BD, Xing Z (2020) "Immunological considerations for COVID-19 vaccine strategies". Nat Rev Immunol 20(10):615-632

18. Juno JA, Tan H-X, Lee WS, Reynaldi A, Kelly HG, Wragg K, Esterbauer R, Kent HE, Batten CJ, Mordant FL (2020) "Humoral and circulating follicular helper T cell responses in recovered patients with COVID-19". Nat Med 26(9):1428-1434

19. Kaur SP, Gupta V (2020) "COVID-19 Vaccine: A comprehensive status report." Virus research: 198114

20. Khorasani A, Madadgar O, Soleimanjahi H, Keyvanfar H, Mahravani H (2016) Evaluation of the efficacy of a new oil-based adjuvant ISA 61 VG FMD vaccine as a potential vaccine for cattle. Iranian journal of veterinary research 17(1):8

21. Khoury DS, Cromer D, Reynaldi A, Schlub TE, Wheatley AK, Juno JA, Subbarao K, Kent SJ, Triccas JA, Davenport MP (2021) "Neutralizing antibody levels are highly predictive of immune protection from symptomatic SARS-CoV-2 infection." Nature medicine: 1-7

22. Logunov DY, Dolzhikova IV, Zubkova OV, Tukhvatullin Al, Shcheblyakov DV, Dzharullaeva AS, Grousova DM, Erokhova AS, Kovyrshina AV, Botikov AG (2020) "Safety and immunogenicity of an rAd26 and rAd5 vector-based heterologous prime-boost COVID-19 vaccine in two formulations: two open, non-randomised phase 1/2 studies from Russia. " The Lancet 396(10255):887-897

23. Lord SJ, Rajotte RV, Korbutt GS, Bleackley RC (2003) Granzyme B: a natural born killer. Immunol Rev 193:31-38

24. Mahdavi M, Ebtekar M, Khorshid HRK, Azadmanesh K, Hartoonian C, Hassan ZM (2011) ELISPOT analysis of a new CTL based DNA vaccine for HIV-1 using GM-CSF in DNA prime/peptide boost strategy: GM-CSF induced long-lived memory responses. Immunol Lett 140(1-2):14-20

25. Mahdavi M, Mavandadnejad F, Yazdi MH, Faghfuri E, Hashemi H, Homayouni-Oreh S, Farhoudi R, Shahverdi AR (2017) Oral administration of synthetic selenium nanoparticles induced robust Th1 
cytokine pattern after HBs antigen vaccination in mouse model. J Infect Public Health 10(1):102109

26. Mahdavi M, Tajik AH, Ebtekar M, Rahimi R, Adibzadeh MM, Moozarmpour HR, Beikverdi MS, Olfat S, Hassan ZM, Choopani M (2017) Granulocyte-macrophage colony-stimulating factor, a potent adjuvant for polarization to Th-17 pattern: an experience on HIV-1 vaccine model. Apmis 125(6):596-603

27. Maspi N, Ghaffarifar F, Sharifi Z, Dalimi A, Dayer MS (2017) Immunogenicity and efficacy of a bivalent DNA vaccine containing LelF and TSA genes against murine cutaneous leishmaniasis. Apmis 125(3):249-258

28. Mojarab S, Shahbazzadeh D, Moghbeli M, Eshraghi Y, Bagheri KP, Rahimi R, Savoji MA, Mahdavi M (2020) Immune responses to HIV-1 polytope vaccine candidate formulated in aqueous and alcoholic extracts of Propolis: Comparable immune responses to Alum and Freund adjuvants. Microb Pathog 140:103932

29. Nao N, Yamagishi J, Miyamoto H, Igarashi M, Manzoor R, Ohnuma A, Tsuda Y, Furuyama W, Shigeno A, Kajihara MJM (2017) "Genetic predisposition to acquire a polybasic cleavage site for highly pathogenic avian influenza virus hemagglutinin." 8(1)

30. Noh G (2020) "Ifn-Gamma as a major antiviral therapeutic for viral epidemics, including severe acute respiratory syndrome coronavirus 2 (SARS-CoV-2): a clinically forgotten but potential antiviral cytokine and non-virus-specific antiviral as a new antiviral strategy."Journal of Clinical Review \& Case Reports5(4)

31. Peng S, Cao F, Xia Y, Gao XD, Dai L, Yan J, Ma G (2020) "Particulate Alum via Pickering Emulsion for an Enhanced COVID-19 Vaccine Adjuvant. " Advanced Materials 32(40):2004210

32. Pfefferbaum B, J. CS (2020) N. E. J. o. M. North "Mental health and the Covid-19 pandemic."

33. Ramasamy MN, Minassian AM, Ewer KJ, Flaxman AL, Folegatti PM, Owens DR, Voysey M, Aley PK, Angus B, Babbage G, Belij-Rammerstorfer S, Berry L, Bibi S, Bittaye M, Cathie K, Chappell H, Charlton S, Cicconi P, Clutterbuck EA, Colin-Jones R, Dold C, Emary KRW, Fedosyuk S, Fuskova M, Gbesemete D, Green C, Hallis B, Hou MM, Jenkin D, Joe CCD, Kelly EJ, Kerridge S, Lawrie AM, Lelliott A, Lwin MN, Makinson R, Marchevsky NG, Mujadidi Y, Munro APS, Pacurar M, Plested E, Rand J, Rawlinson T, Rhead S, Robinson H, Ritchie AJ, Ross-Russell AL, Saich S, Singh N, Smith CC, Snape MD, Song R, Tarrant R, Themistocleous Y, Thomas KM, Villafana TL, Warren SC, Watson MEE, Douglas AD, Hill AVS, Lambe T, Gilbert SC, Faust SN, Pollard AJ (2021) Safety and immunogenicity of ChAdOx1 nCoV-19 vaccine administered in a prime-boost regimen in young and old adults (COV002): a singleblind, randomised, controlled, phase 2/3 trial. Lancet 396(10267):1979-1993

34. Rasmussen SA, Kelley CF, Horton JP, Jamieson DJ (2021) "Coronavirus Disease 2019 (COVID-19) Vaccines and Pregnancy: What Obstetricians Need to Know. " Obstet Gynecol 137(3):408-414

35. Riteau N, Radtke AJ, Shenderov K, Mittereder L, Oland SD, Hieny S, Jankovic D, Sher A (2016) Waterin-oil-only adjuvants selectively promote $T$ follicular helper cell polarization through a type I IFN and IL-6-dependent pathway. J Immunol 197(10):3884-3893 
36. Rostami H, Ebtekar M, Ardestani MS, Yazdi MH, Mahdavi M (2017) Co-utilization of a TLR5 agonist and nano-formulation of HIV-1 vaccine candidate leads to increased vaccine immunogenicity and decreased immunogenic dose: A preliminary study. Immunol Lett 187:19-26

37. Savoji MA, Haghighat S, Mirzaee M, Golkaran B, Mirzaee R, Esfandiari B, Mahdavi M (2019) "Formulation of HBs antigen in Montanide ISA266 shows superiority to commercial HBsAg vaccine in the induction of humoral immune responses." Gastroenterology and hepatology from bed to bench 12(4): 292

38. Savoji MA, Sereshgi MMA, Ghahari SMM, Asgarhalvaei F, Mahdavi M (2021) Formulation of HBsAg in Montanide ISA 51VG adjuvant: Immunogenicity study and monitoring long-lived humoral immune responses. Int Immunopharmacol 96:107599

39. Serre K, Mohr E, Gaspal F, Lane PJ, Bird R, Cunningham AF, MacLennan IC (2010) "IL-4 directs both CD 4 and CD8 T cells to produce Th2 cytokines in vitro, but only CD4 T cells produce these cytokines in response to alum-precipitated protein in vivo". Mol Immunol 47(10):1914-1922

40. Shi Y, Wang G, Cai XP, Deng JW, Zheng L, Zhu HH, Zheng M, Yang B, Chen Z (2020) "An overview of COVID-19". J Zhejiang Univ Sci B 21(5):343-360

41. Soema PC, van Riet E, Kersten G, Amorij J-P (2015) Development of cross-protective influenza A vaccines based on cellular responses. Front Immunol 6:237

42. Starr TN, Czudnochowski N, Zatta F, Park Y-J, Liu Z, Addetia A, Pinto D, Beltramello M, Hernandez P, Greaney AJ (2021) "Antibodies to the SARS-CoV-2 receptor-binding domain that maximize breadth and resistance to viral escape." bioRxiv

43. Trouillet-Assant S, Viel S, Gaymard A, Pons S, Richard J-C, Perret M, Villard M, Brengel-Pesce K, Lina B, Mezidi MJJ, Immunology C (2020) "Type I IFN immunoprofiling in COVID-19 patients." 146(1): 206208. e202

44. Wang J, Peng Y, Xu H, Cui Z, Williams RO (2020) "The COVID-19 vaccine race: challenges and opportunities in vaccine formulation". AAPS PharmSciTech 21(6):1-12

45. Wang LF, Shi Z, Zhang S, Field H, Daszak P, Eaton BT (2006) "Review of bats and SARS " Emerg Infect Dis 12(12):1834-1840

46. Zheng H-Y, Zhang M, Yang C-X, Zhang N, Wang X-C, Yang X-P, Dong X-Q, Zheng Y-T (2020) Elevated exhaustion levels and reduced functional diversity of $T$ cells in peripheral blood may predict severe progression in COVID-19 patients. Cell Mol Immunol 17(5):541-543

47. Zhu F-C, Li Y-H, Guan X-H, Hou L-H, Wang W-J, Li J-X, Wu S-P, Wang B-S, Wang Z, Wang L (2020) "Safety, tolerability, and immunogenicity of a recombinant adenovirus type- 5 vectored COVID-19 vaccine: a dose-escalation, open-label, non-randomised, first-in-human trial". The Lancet 395(10240):1845-1854

\section{Figures}




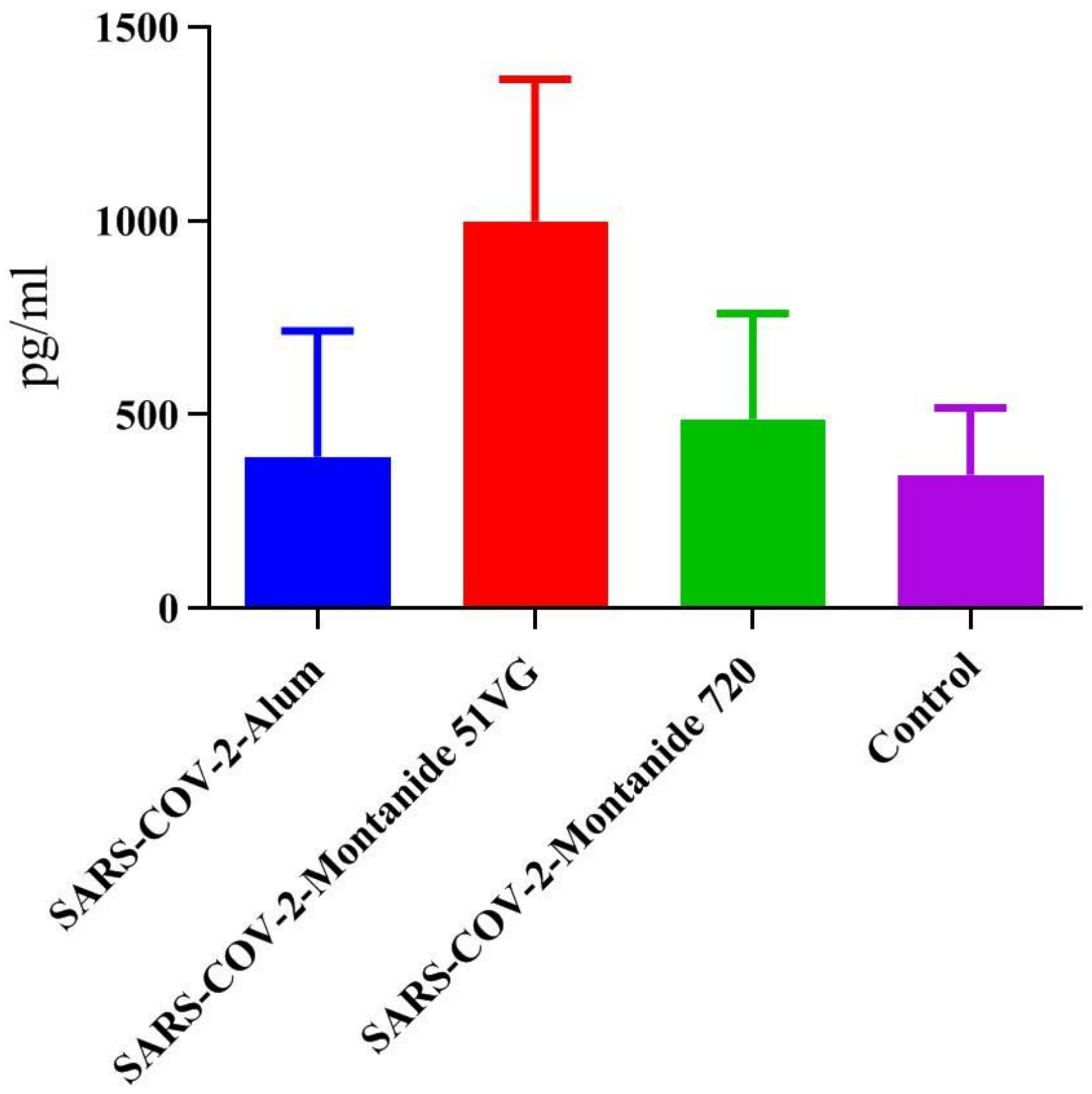

\section{Experimental groups}

Figure 1

The results of IFN-y cytokine in the experimental groups. Immunization with SARS-COV-2-Montanide ISA$51 \mathrm{VG}$ shows a significant increase versus control group $(\mathrm{P}=0.0003)$. In addition, immunization with SARS-COV-2-Montanide ISA-51VG showed a significant increase in IFN- $\gamma$ response as compared with SARS-COV-2-Alum and SARS-COV-2Montanide ISA-720VG groups ( $P=0.0004$ and $P=0.0033$, respectively). 


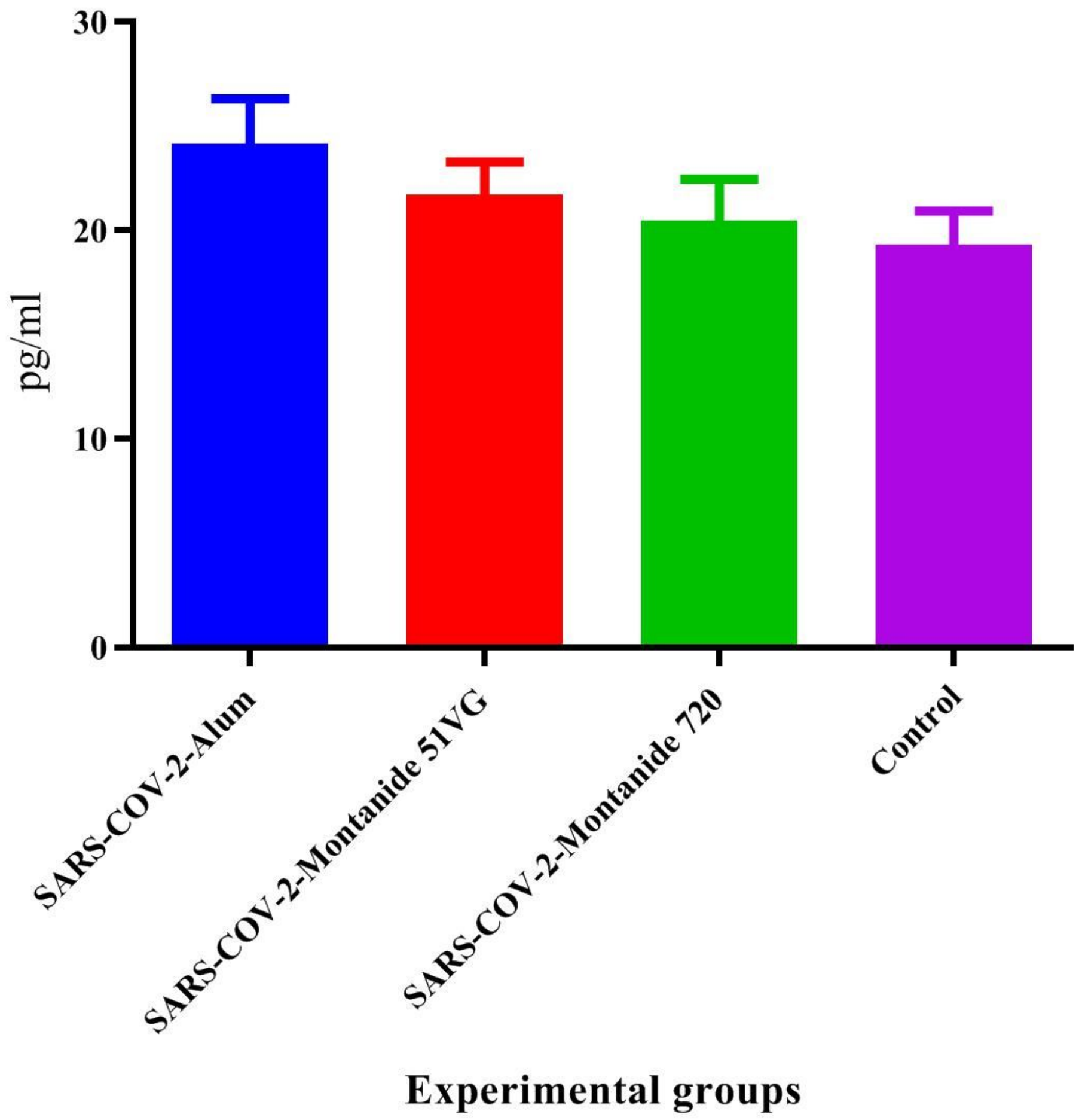

Figure 2

Immunization with SARS-COV-2-Alum and SARS-COV-2-Montanide ISA-51VG vaccine showed a significant increase in IL-4 cytokine response versus control group ( $P=0.0001$ and $P=0.0288$, respectively). Furthermore, immunization with SARS-COV-2-Alum vaccine showed a significant increase of IL-4 cytokine response in comparison with SARS-COV-2-Montanide ISA-51VG and SARS-COV-2-Montanide ISA-720VG vaccines $(P=0.0206$ and $P=0.0005$, respectively). 


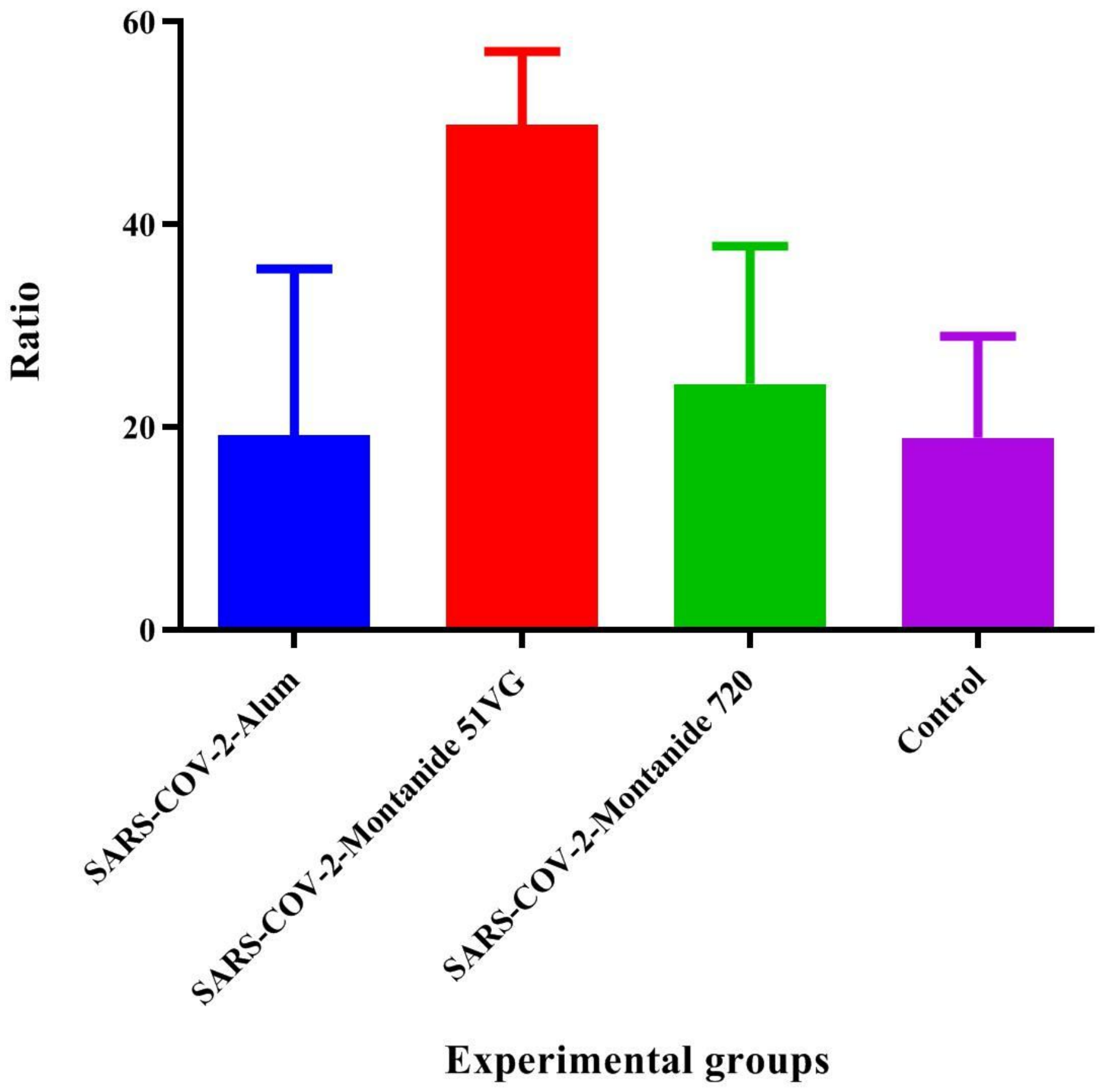

Figure 3

The results of IFN- $\mathrm{Y} / \mathrm{IL}-4$ cytokine ratio in the experimental groups. Immunization with SARS-COV-2Montanide ISA-51VG vaccine showed a significant increase in IFN- $/ / \mathrm{LL}-4$ cytokine ratio in comparison with SARS-COV-2-Alum, SARS-COV-2-Montanide ISA-720VG and control group $(P=0.0001, P=0.0004$ and $P=0.0001$, respectively). 


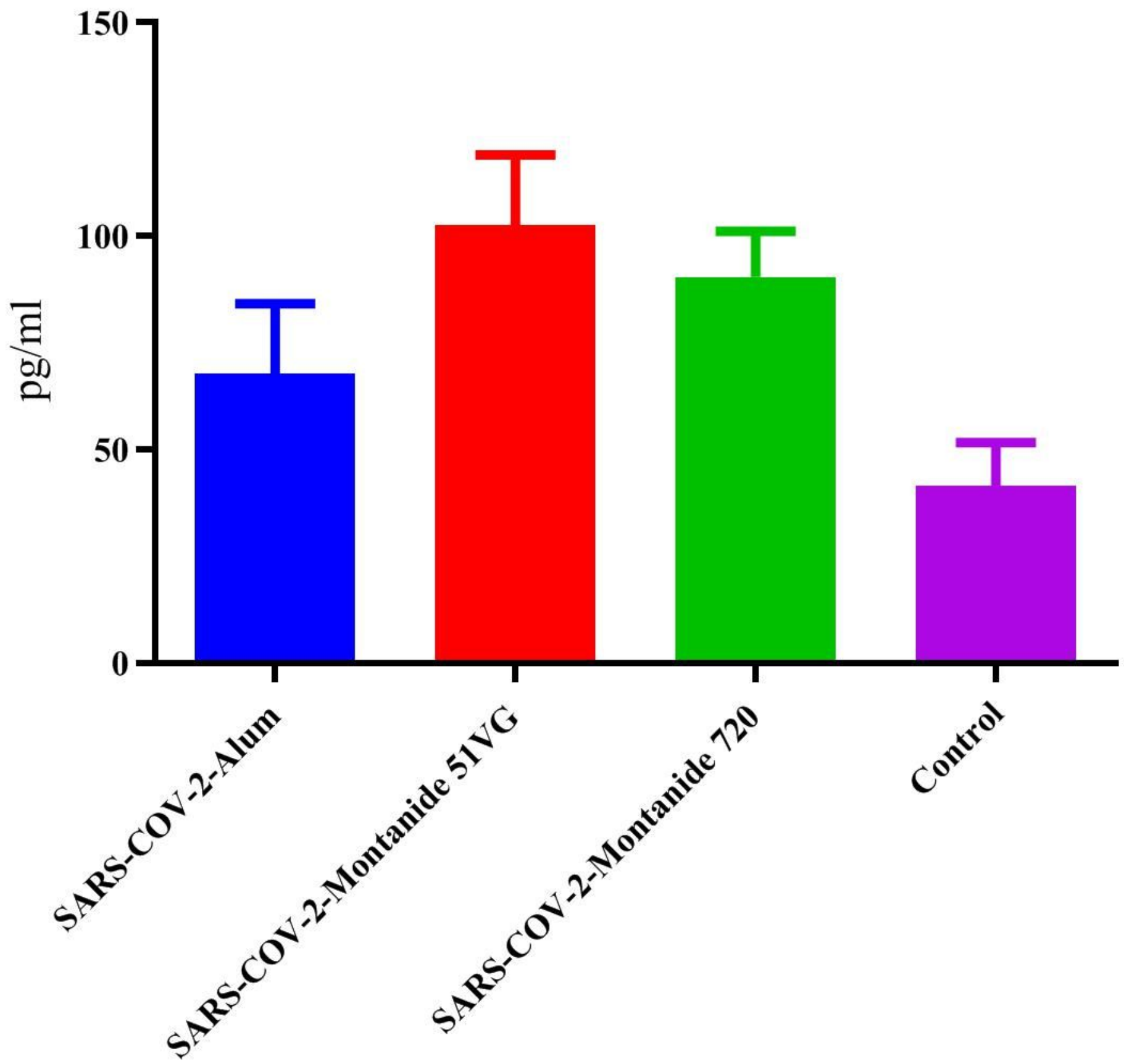

\section{Experimental groups}

\section{Figure 4}

The results of CTL activity based on Gr-B secretion in the mice. Immunization with SARS-COV-2Montanide ISA-51VG, SARS-COV-2-Alum and SARS-COV-2-Montanide ISA-720VG vaccines showed a significant increase versus control group ( $P=0.0001, P=0.0017$ and $P=0.0001$, respectively). In addition, immunization with SARS-COV-2-Montanide ISA51VG and SARS-COV-2-Montanide ISA 720VG vaccines showed a significant increase in comparison with SARS-COV-2-Alum group $(P=0.0001$ and $P=0.0075$, 
respectively). But no significant difference in CTL activity was observed between SARS-COV-2 Montanide ISA-51VG and SARS-COV-2 Montanide ISA-720VG groups ( $P=0.2628)$.

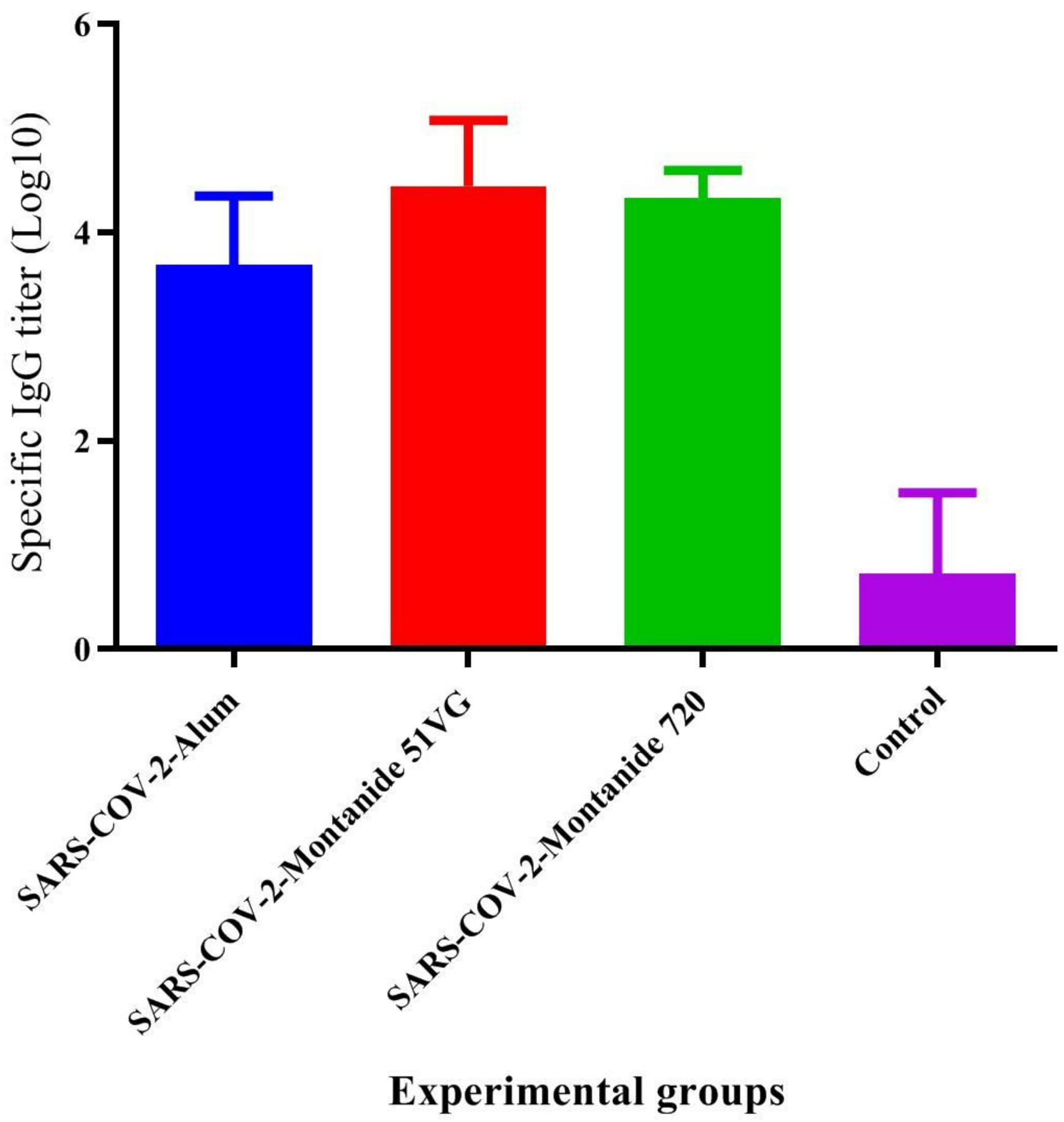

Figure 5

The results of specific IgG titer in the experimental groups based on the end-point in ELISA. Immunization with SARS-COV-2-Montanide ISA-51VG, SARS-COV-2-Alum and SARS-COV-2-Montanide ISA -720VG vaccines showed a significant increase versus control group $(P<0.0001)$. Furthermore, immunization with SARS-COV-2-Montanide ISA-51VG and SARS-COV-2-Montanide ISA-720VG vaccines demonstrated a 
significant increase in specific IgG titer in comparison with SARS-COV-2-Alum group ( $P=0.0143$ and $\mathrm{P}=0.0048$, respectively). There was no significant difference in specific IgG titer between SARS-COV-2 Montanide ISA-51VG and SARS-COV-2 Montanide ISA-720VG groups $(\mathrm{P}=0.6867)$.

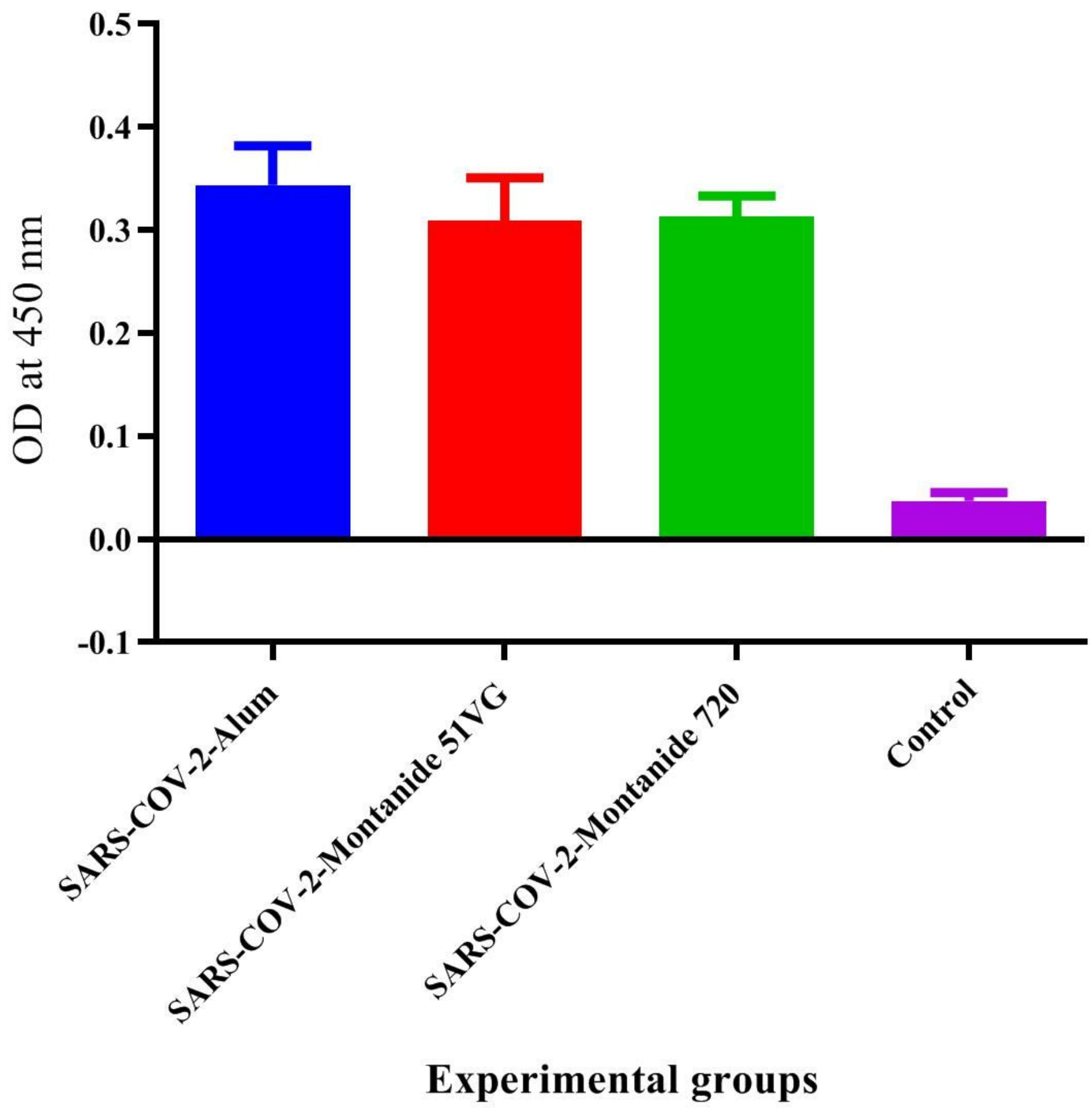

Figure 6

The results of specific IgG1 isotype antibody in the experimental groups. Immunization with SARS-COV-2Montanide ISA-51VG, SARS-COV-2-Alum and SARS-COV-2-Montanide ISA-720VG vaccines showed a 
significant increase versus control group $(P<0.0001)$. The group immunized with SARS-COV-2-Alum showed a significant increase in IgG1 isotype response in comparison with SARS-COV-2-Montanide ISA51VG and SARS-COV-2-Montanide ISA-720VG vaccines ( $P=0.0043$ and $P=0.0041$, respectively).

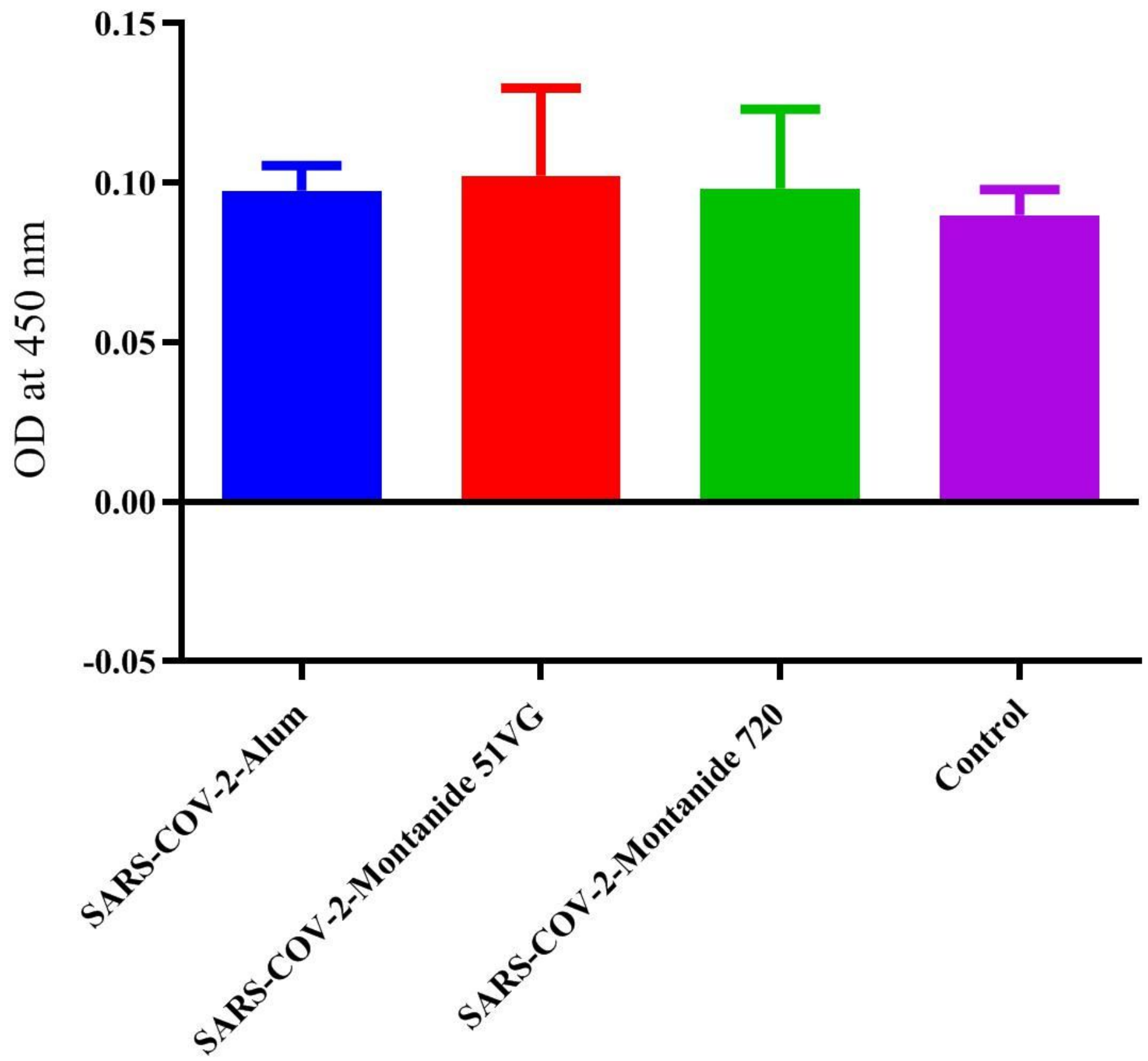

Experimental groups

Figure 7

The results of specific IgG2a isotype antibody in the experimental groups. Immunization with SARS-COV2-Montanide ISA51VG, SARS-COV-2-Alum and SARS-COV-2-Montanide ISA 720VG vaccines showed a 
small increase versus control group but no significant differences was observed among experimental groups $(P>0.1550)$.

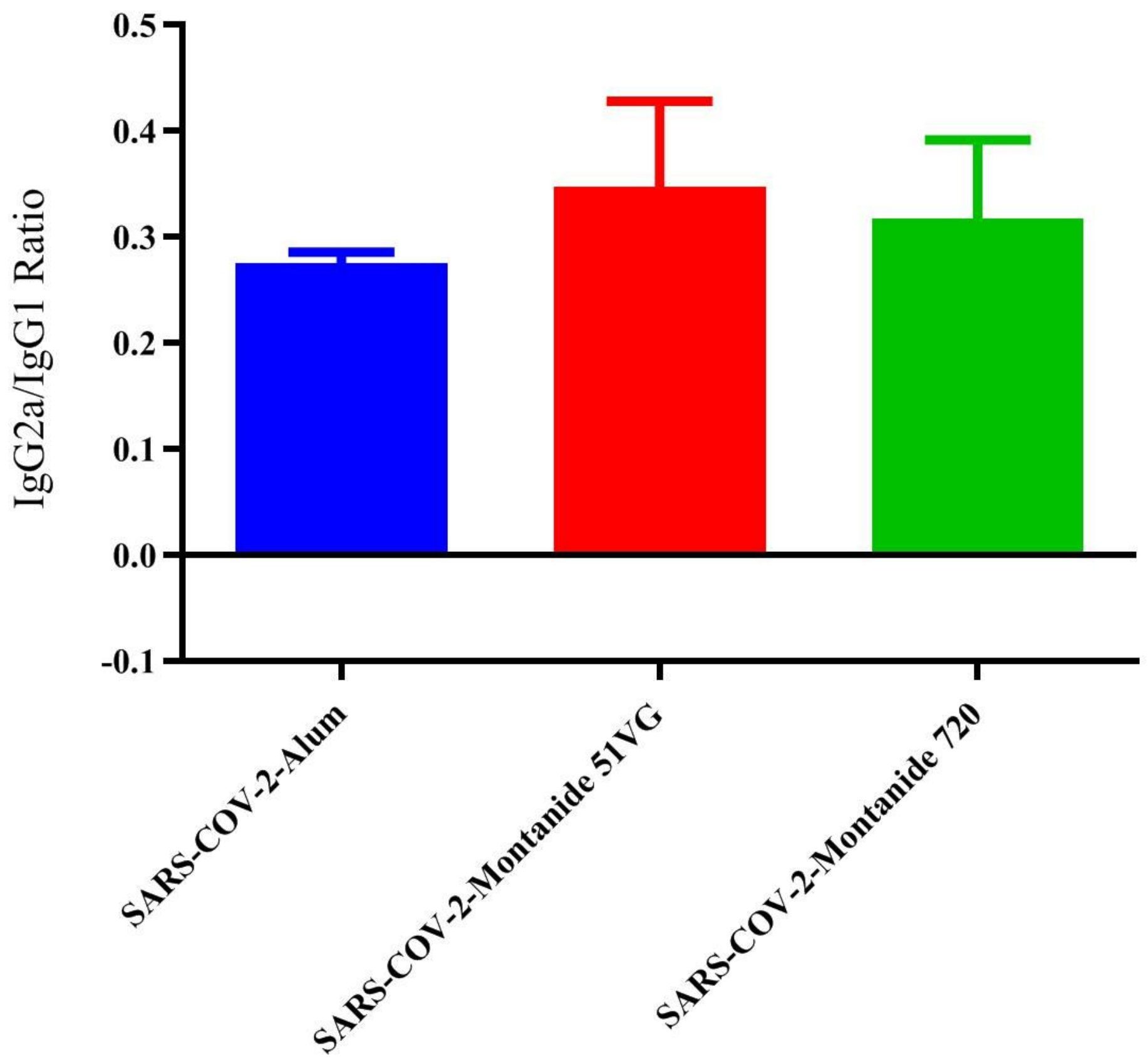

Experimental groups

Figure 8

The results of IgG2a/lgG1 ratio in the experimental groups. Immunization with SARS-COV-2-Montanide ISA-51VG and SARS-COV-2-Montanide ISA-720VG vaccines resulted to a significant increase in $\lg \mathrm{G} 2 \mathrm{a} / \mathrm{IgG} 1$ ratio versus SARS-COV-2-Alum group $(\mathrm{P}=0.0379$ and $\mathrm{P}=0.0175$, respectively). While there was 
no significant difference in IgG2a/IgG1 ratio between SARS-COV-2 Montanide ISA51VG and SARS-COV-2 Montanide ISA720VG groups $(P=0.4458)$.

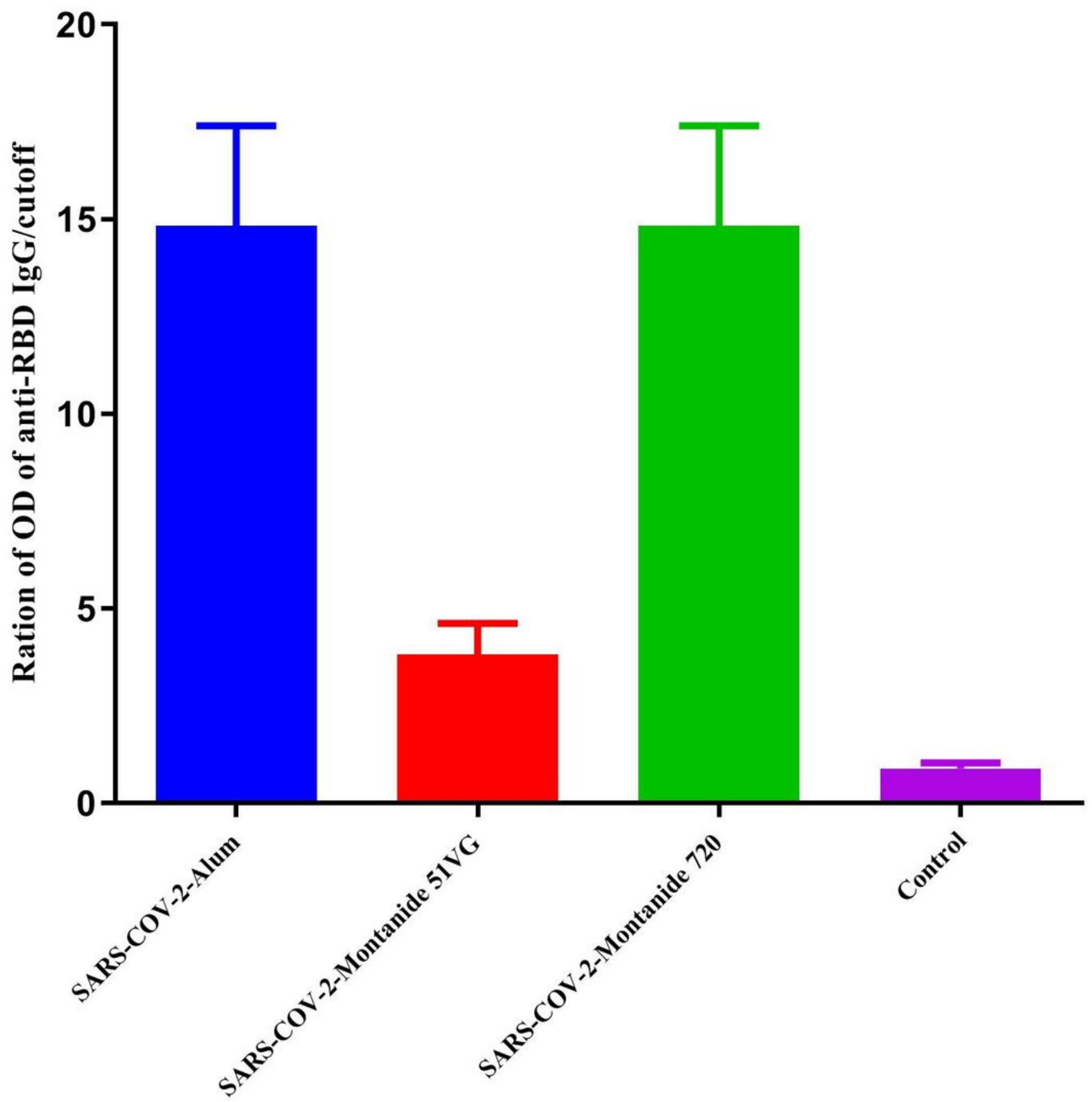

Experimental groups

Figure 9

Results from specific IgG antibodies against RBD protein which reported as ratio of OD of RBD ELISA of individual mouse/cutoff. Immunization with inactivated SARS-COV-2+Alum and SARS-COV-2-Montanide ISA 720VG vaccines showed a significant increase versus SARS-COV-2-Montanide ISA51VG group 
$(\mathrm{P}<0.0001)$. While SARS-COV-2-Alum and SARS-COV-2-Montanide ISA 720VG groups showed a comparable IgG response in anti-RBD IgG response and did not show a significant difference versus each other $(P=0.9999)$. 